\title{
Propiedad Intelectual y Derechos Humanos. Hacia un sistema de derechos de autor que promueva los derechos culturales
}

\author{
Beatriz BUSANICHE
}

Editorial: Tren en Movimiento. Temperley, Argentina.

Año: 2016

Páginas: 112

ISBN: 978-987-3789-20-5

El libro Propiedad intelectual y derechos humanos, que Beatriz Busaniche publicó en Argentina durante el año 2016, trabaja sobre una normatividad conflictiva en el derecho internacional y hace un análisis detallado de la tensión en ese campo. Las consecuencias de este, sin embargo, superan el ámbito del derecho, y se transforman hoy en asuntos fundamentales para la educación, la cultura y la comunicación. Nos interesa proponer la lectura de este texto en tanto consideramos hoy su importancia en el marco de lo que comúnmente se llama Sociedad de la Información.

La incorporación de las tecnologías de la información y la comunicación en los procesos productivos, la creciente difusión del saber y la cultura, el desarrollo de la conexión en red, la captación y valorización del registro de la experiencia vital humana a través de empresas de tecnología, entre otros rasgos que conforman el modo de producción actual, nos llevan a repensar los mecanismos de privatización de los productos del trabajo social humano, tal como lo son los bienes culturales. Los regímenes legales de propiedad intelectual aportan a una política de cercamiento sobre la difusión de los bienes intangibles, con el objetivo de crear sobre ellos una escasez artificial que permita su valorización como capital.

La autora nos plantea un análisis de la relación, al menos tensa, entre los órdenes de la propiedad intelectual, en especial el derecho de autor, y los derechos culturales incluidos en las disposiciones y acuerdos sobre derechos 
humanos. Lo hace además desde una perspectiva histórica, la cual está marcada en las últimas décadas por el Acuerdo sobre los Aspectos de los Derechos de Propiedad Intelectual relacionados con el Comercio (ADPIC). Este acuerdo fue incorporado a las legislaciones de los países que conforman la OMC (a veces de forma muy restrictiva, como es el caso de Argentina). Sin embargo, las múltiples contradicciones de este ordenamiento para la protección de la propiedad autoral -en tanto individuos o corporaciones- respecto al articulado de los derechos humanos han resultado en fuertes críticas en los ámbitos del activismo político y social, y en el mundo académico. De acuedo a V. Delich (p. 8), prologuista del libro, las normas de propiedad intelectual están en crisis por tres factores simultáneos:

a. el reordenamiento del modo de producción contemporáneo en la cadena de valor de la cultura, donde la apropiación legal monopólica no siempre resulta efectiva ni apropiada para fomentar nuevas formas de producción de conocimiento innovador;

b. las prácticas sociales, que privilegian la reutilización de contenido y el acceso a través de la red por sobre el respeto a normas legales que la mayoría de las veces los ciudadanos desconocen;

c. las políticas de los países en desarrollo, que en la operacionalización de derechos humanos como la salud, la alimentación, deciden implementar políticas públicas que acotan el campo de acción de las normas de propiedad intelectual, o en todo caso, mitigan sus efectos a través de políticas laissez faire allí donde se producen infracciones.

El incentivo a la creación, la distribución del conocimiento y el uso social de los avances son tres aspectos que han tensionado la relación analizada. Esta tirantez ha resultado más evidente cuando se discuten los derechos de acceso a la educación y la salud (por ejemplo, las patentes sobre nuevos descubrimientos médicos muchas veces hacen económicamente insostenible su acceso para las poblaciones necesitadas). Este texto propone el estudio de un campo algo soslayado, quizás por su deficiente nivel de operacionalización: los derechos culturales.

El libro es un ensayo de poco más de cien páginas. Además de un exhaustivo recorrido por las discusiones que dieron origen a los regímenes legales de hoy, tiene el mérito de finalizar con una propuesta de política pública; en este caso, para la legislación argentina. Cuenta con tres capítulos.

En el primero se retoma el tratamiento de los derechos culturales en el marco de la Declaración Universal de los Derechos Humanos, de 1948, y en el Pacto Internacional de Derechos Económicos, Sociales y Culturales (Pidesc), de 1966. Se entiende que los textos finales de sus -respectivamente- artículos 27 y 15 fueron resultado de un diferente nivel de conformidad: el primer segmento de esos artículos -el derecho a tomar parte libremente de la vida cultural de 
una comunidad y a disfrutar de los beneficios del progreso científico- tuvo un acuerdo casi unánime. Su segunda parte -sobre la protección de los intereses morales y patrimoniales de los autores- llevó a mayores discusiones, que incluso sugieren la existencia de alguna contradicción al interior de esos párrafos. Sin embargo, se menciona que el Comité de Aplicación del Pacto ha enfatizado que estos códigos no proponen a los Estados una única manera de defender estos intereses de los autores; y que, en todos los casos se refieren a personas físicas y no jurídicas. Es decir, la propiedad intelectual, tal como se comprende en el ADPIC no es un derecho humano, y no se debería comprender en el mismo nivel que el derecho de acceso a la cultura y la ciencia.

El segundo capítulo, analiza la diferente elaboración de la relación entre los derechos humanos y los derechos de autor, desde las hipótesis de conflicto o posible coexistencia. Finalmente, en el tercer capítulo la autora presenta una propuesta de política pública sobre derechos de autor para la Argentina, en donde menciona tres ejes programáticos a considerar en una eventual modificación de la legislación sobre propiedad intelectual: la importancia de reformular la relación de los autores, la industria y sus representantes corporativos; pensar el vínculo entre los titulares de derechos y la ciudadanía; y por último, redefinir el rol del Estado en la promoción de políticas culturales.

Para finalizar, consideramos necesario una vez más valorar este aporte para la nuevas problemáticas del campo de la cultura, el conocimiento y la comunicación en la actualidad.

\section{María José AGUIRRE MORENO}

morenomajo@gmail.com 